\title{
A long-term evaluation of once-daily inhaled tiotropium in chronic obstructive pulmonary disease
}

\author{
R. Casaburi*, D.A. Mahler", P.W. Jones ${ }^{\star}$, A. Wanner ${ }^{+}$, G. San Pedro ${ }^{\S}$, R.L. ZuWallack ${ }^{f}$, \\ S.S. Menjoge**, C.W. Serby**, T. Witek Jr**
}

A long-term evaluation of once-daily inhaled tiotropium in chronic obstructive pulmonary disease. R. Casaburi, D.A. Mahler, P.W. Jones, A. Wanner, G. San Pedro, R.L. ZuWallack, S.S. Menjoge, C.W. Serby, T. Witek Jr. (C) ERS Journals Ltd 2002.

ABSTRACT: Currently available inhaled bronchodilators used as therapy for chronic obstructive pulmonary disease (COPD) necessitate multiple daily dosing. The present study evaluates the long-term safety and efficacy of tiotropium, a new once-daily anticholinergic in COPD.

Patients with stable COPD (age 65.2 \pm 8.7 yrs $(\operatorname{mean} \pm \mathrm{SD}), \mathrm{n}=921$ ) were enrolled in two identical randomized double-blind placebo-controlled 1-yr studies. Patients inhaled tiotropium $18 \mu \mathrm{g}$ or placebo (mean screening forced expiratory volume in one second (FEV1) 1.01 versus $0.99 \mathrm{~L}, 39.1$ and $38.1 \%$ of the predicted value) once daily as a dry powder. The primary spirometric outcome was trough FEV1 (i.e. FEV1 prior to dosing). Changes in dyspnoea were measured using the Transition Dyspnea Index, and health status with the disease-specific St. George's Respiratory Questionnaire and the generic Short Form 36. Medication use and adverse events were recorded.

Tiotropium provided significantly superior bronchodilation relative to placebo for trough FEV1 response $(\sim 12 \%$ over baseline) $(p<0.01)$ and mean response during the $3 \mathrm{~h}$ following dosing $(\sim 22 \%$ over baseline $)(p<0.001)$ over the 12 -month period. Tiotropium recipients showed less dyspnoea $(p<0.001)$, superior health status scores, and fewer COPD exacerbations and hospitalizations $(p<0.05)$. Adverse events were comparable with placebo, except for dry mouth incidence (tiotropium $16.0 \%$ versus placebo $2.7 \%$, $\mathbf{p}<\mathbf{0 . 0 5 )}$.

Tiotropium is an effective, once-daily bronchodilator that reduces dyspnoea and chronic obstructive pulmonary disease exacerbation frequency and improves health status. This suggests that tiotropium will make an important contribution to chronic obstructive pulmonary disease therapy.

Eur Respir J 2002; 19: 217-224.

Chronic obstructive pulmonary disease (COPD) is characterized by reduced expiratory airflow and the symptoms of cough, sputum production and dyspnoea [1]. The breathlessness associated with COPD develops over many years, is a major reason for seeking medical care and eventually limits daily activities [2].

Bronchodilators are the mainstay of drug therapy for COPD given their ability to improve airflow and reduce breathlessness, the latter probably being related to reduced hyperinflation [3]. Inhaled anticholinergic drugs such as ipratropium have been used since the 1970s in COPD and have emerged as a safe and effective therapy [1, 4]. A limitation of these agents is the need for frequent (i.e. four times daily) dosing. Tiotropium, an agent in a new class of anticholinergics, exhibits a longer duration of action due to prolonged muscarinic receptor antagonism [5, 6]. These effects have the therapeutic advantage of
*Harbor-UCLA Research and Education Institute, Torrance, CA, " Dartmouth Hitchcock Medical Center Lebanon, $\mathrm{NH},{ }^{+}$University of Miami School of Medicine, Miami, FL, ${ }^{\S}$ Louisiana State University Medical Center, Shreveport, LA, ${ }^{f}$ St Francis Hospital and Medical Center, Hartford, CT, and **Boehringer Ingelheim Pharmaceuticals, Inc., Ridgefield, CT, USA. 'St George's Hospital, London, UK

Correspondence: R. Casaburi, HarborUCLA Research and Education Institute, Building RB-2, $1124 \mathrm{~W}$. Carson Street, Torrance, CA 90502, USA.

Fax: 13103289849

E-mail: casaburi@ucla.edu

Keywords: Chronic obstructive pulmonary disease dyspnoea

exacerbations

quality of life

tiotropium

Received: August 92001

Accepted after revision November 2 2001

This study was supported by Boehringer Ingelheim Pharmaceuticals, Inc. making once-daily dosing a possibility [7]. The present article reports 1-yr data concerning the efficacy and safety of tiotropium in COPD patients in terms of bronchodilation, symptoms and other health outcomes including adverse events. It characterizes tiotropium as a new therapy for COPD.

\section{Methods}

\section{Study design and conduct}

Two identical clinical trials were designed to establish the efficacy and safety of tiotropium (Spiriva $\mathbb{R}$; Boehringer Ingelheim, Ingelheim am Rhein, Germany), including health outcomes. These two trials have been combined in the present report to provide a comprehensive efficacy and safety profile. Fifty clinical centres participated in the double-blind 
placebo-controlled trials. These trials were approved by each centre's Institutional Review Board. All patients provided written informed consent.

The study groups consisted of outpatients of either sex who were $\geqslant 40$-yrs-old and had a clinical diagnosis of COPD, as defined by the American Thoracic Society (ATS) [8]. Participants were required to have at least a 10 pack-yr smoking history, clinically stable airway obstruction, and a forced expiratory volume in one second (FEV1) of $\leqslant 65 \%$ of predicted normal values and $\leqslant 70 \%$ of forced vital capacity (FVC). Patients were excluded if they had a history of asthma, allergic rhinitis or atopy or a total blood eosinophil count of $\geqslant 600$ cells $\cdot \mathrm{mm}^{-3}$. Bronchodilator responsiveness was not an entry criterion. Patients were also excluded if they required regular daytime supplemental oxygen or were on doses exceeding the equivalent of $10 \mathrm{mg}$ prednisone daily during the month prior to entering the study. In addition, patients were excluded if they had a recent history of myocardial infarction $(\leqslant 1 \mathrm{yr})$, heart failure $(\leqslant 3 \mathrm{yrs})$ or cardiac arrhythmia requiring drug therapy.

\section{Treatments}

Following a 2-week baseline period, patients were randomly assigned within each study centre to receive either tiotropium $(18 \mu \mathrm{g})$ or placebo. Patients were randomized in a 3:2 tiotropium:placebo ratio in order to expose a greater number of patients to tiotropium for safety evaluation. Subjects took, by inhalation, active medication (tiotropium in lactose) or placebo (lactose) once each morning from identically appearing capsules via a dry powder inhaler device (HandiHaler $\mathbb{R}$; Boehringer Ingelheim, Ingelheim am Rhein, Germany) [9]. Patients were permitted an albuterol metered-dose inhaler, as needed, stable doses of theophylline (i.e. unchanging doses that had been used for $\geqslant 6$ weeks prior to entry), inhaled glucocorticosteroids and the equivalent of $\leqslant 10 \mathrm{mg} \cdot \mathrm{day}^{-1}$ oral prednisone throughout the study period. Finally, to treat acute COPD exacerbations during the trial, investigators were permitted to administer any additional medication deemed necessary (excluding anticholinergic or long-acting $\beta$-agonists). After 13 weeks, the investigators were permitted to prescribe glucocorticosteroids or theophylline preparations as necessary.

\section{Spirometric testing}

Spirometric testing was conducted on treatment day 1 and after 1, 7, 13, 25, 37 and 49 weeks of therapy. Drug was administered at the same time each day (between 07:00 and 09:00 h). On test days, FEV1 and FVC were recorded $1 \mathrm{~h}$ prior to dosing, just prior to dosing, and 30,60, 120 and $180 \mathrm{~min}$ after study drug administration. Spirometric manoeuvres were conducted in triplicate and the greatest FEV1 and FVC used in subsequent analyses. Predicted normal values for FEV1 and FVC were derived from standard equations [10]. Spirometers were required to meet ATS standards [11].
In order to ensure standardized conditions on spirometric test days, subjects discontinued theophylline $24 \mathrm{~h}$ prior to spirometric testing (compliance was assessed by measuring theophylline levels prior to testing and noting patients with levels of $\geqslant 5.0 \mu \mathrm{g} \cdot \mathrm{mL}^{-1}$; this threshold was exceeded in only $12 \%$ of measurements). Albuterol and inhaled corticosteroids were stopped $\geqslant 12 \mathrm{~h}$ prior to spirometric testing.

\section{Other observations}

Before entry and upon trial completion, patients underwent medical history checks, physical examination, and routine blood chemistry and haematology testing as well as 12-lead electrocardiography to exclude other important diseases and to monitor study medication safety. Each subject also performed peak expiratory flow rate (PEFR) measurements in their home twice daily (upon arising and at bedtime) using the AirWatch ${ }^{\mathrm{TM}}$ Monitor (Enact Health Management Systems, Mountain View, CA, USA). Study clinic visits were scheduled on the first day of study drug administration, at the end of the first week of therapy, every 3 weeks thereafter throughout the first 13 weeks of treatment and every 6 weeks for the next 36 weeks, in order to assess adverse events, concomitant medication use and clinical status. An exacerbation, detected through monitoring of adverse events, was defined as a complex of respiratory events (i.e. cough, wheezing, dyspnoea or sputum production) lasting $>3$ days. These were generally treated with antibiotics and/or oral steroids.

\section{Diary and interview assessments}

Dyspnoea at baseline was assessed using the Baseline Dyspnea Index (BDI) [12]. This instrument has three domains (functional impairment, magnitude of task and magnitude of effort), the sum of the values giving a combined focal score. Changes in impairment from baseline were measured using the Transition Dyspnea Index (TDI) [12] on days 50 and 90 and every 3 months thereafter. Generic and diseasespecific health status was evaluated by patients using Short Form 36 (SF-36) [13] and St George's Respiratory Questionnaire (SGRQ) [14]. At each visit during the treatment period, the investigator recorded COPD symptom scores after reviewing the patient's daily diary (for wheezing, shortness of breath, coughing and chest tightness) and recorded a global evaluation of the patient's overall condition (1: poor; 8: excellent).

\section{Statistical analysis}

The statistical model was an analysis of covariance with terms for treatment, clinic and baseline as covariates. Discontinuation rates and proportions of patients showing clinically meaningful responses were compared across treatment groups using Fisher's 
exact test. Proportions of patients experiencing at least one COPD exacerbation and hospitalization associated with such exacerbations were compared across treatment groups using logistic regression analysis. Only those COPD exacerbations recorded as adverse events were used for comparison in order to eliminate day-to-day fluctuations in symptoms. The intention-to-treat principle of including all randomized patients was used in all efficacy analyses. Patients who had missing baseline data, or $<2$ weeks of data for certain end points, were excluded from the 1-yr comparisons for those end points. Patients who were unable to complete all of their visits due to drug expiration discontinued their study drug at the 9-month visit but were considered complete patients. When patients discontinued due to worsening of disease (5\% of patients), missing data were imputed using the least favourable data observed prior to discontinuation. In all other cases, missing data following patient withdrawal were imputed by carrying the last observation forward. In order to assess the impact of imputation, data were also analysed based on patients who completed the study to 12 months alone. This sensitivity analysis showed that the results were consistent with those obtained after imputation of missing data.

\section{Sample size}

A sample size of 60 patients per group was calculated as adequate to detect a difference of $0.13 \mathrm{~L}$ in trough FEV1 based on an SD of $0.215 \mathrm{~L}$. To ensure adequate safety exposure, a sample size of 240 patients was selected for each trial.

\section{Results}

Of 921 patients enrolled $(\mathrm{n}=550$ for tiotropium; $n=371$ for placebo), a higher percentage completed the study in the tiotropium group $(81.3 \%)$ than in the placebo group $(72.2 \%)(\mathrm{p}<0.05)$. A lower percentage failed to complete due to adverse events $(9.6 \%)$ and lack of efficacy $(2.4 \%)$ in the tiotropium group than in the placebo group (13.7 and $7.0 \%$, respectively) $(\mathrm{p}<0.05$ for both). In addition, $24 \%$ of patients discontinued the trial prior to the end of the study due to drug expiration. Although further supply of the study drug was originally planned, it was deemed unnecessary as the target sample size was attained due to the lower-than-expected frequency of early withdrawals.

The study population characteristics are listed in table 1. Patients were generally in their seventh decade of life, had a mean cigarette exposure of 61 pack-yrs and a mean FEV1 of $1.02 \mathrm{~L}$, and were predominantly male. Groups were balanced for all characteristics.

\section{Spirometry}

Tiotropium produced acute bronchodilation upon initial dosing superior to that produced by placebo
Table 1.-Demographics and baseline characteristics of the randomized patients

\begin{tabular}{lcc}
\hline & Tiotropium & Placebo \\
\hline Patients n & 550 & 371 \\
Sex male/female & $366 / 184$ & $233 / 138$ \\
Age yrs & $65 \pm 9$ & $65 \pm 9$ \\
Height cm & $171.1 \pm 9.6$ & $170.5 \pm 9.5$ \\
Weight kg & $76.9 \pm 17.7$ & $75.5 \pm 17.5$ \\
Smoking history & $63 \pm 31$ & $59 \pm 30$ \\
pack-yrs & & \\
Duration of & $8.6 \pm 7.4$ & $8.1 \pm 6.8$ \\
disease yrs & $1.04 \pm 0.41$ & $1.00 \pm 0.44$ \\
FEV1 L & $39.1 \pm 13.7$ & $38.1 \pm 14.1$ \\
FEV1 \% pred & $2.31 \pm 0.79$ & $2.23 \pm 0.78$ \\
FVC L & $45.8 \pm 11.6$ & $45.5 \pm 11.6$ \\
FEV1/FVC \% & & \\
Prestudy medication for & & \\
COPD n (\%) & $302(55)$ & $217(59)$ \\
Anticholinergics & $546(99)$ & $368(99)$ \\
$\beta_{2}$-agonist, inhaled & $239(44)$ & $149(40)$ \\
Inhaled steroids & $31(6)$ & $33(9)$ \\
Oral steroids & $123(22)$ & $94(25)$ \\
Theophylline &
\end{tabular}

Data are presented as mean \pm SD unless otherwise indicated. No significant differences were seen between the two groups. FEV1: forced expiratory volume in one second; FVC: forced vital capacity; COPD: chronic obstructive pulmonary disease; \% pred: percentage of the predicted value.

$(\mathrm{p}<0.01)$ (fig. 1). With chronic therapy, predose FEV1 (i.e. trough) was elevated $110 \pm 10-130 \pm 10 \mathrm{~mL}$ $(11 \pm 1-13 \pm 1 \%)$ over baseline (mean \pm SEM); this was superior to placebo by $120 \pm 10-150 \pm 20 \mathrm{~mL}(\mathrm{p}<0.01)$ on the various assessment days. Significant differences from placebo were also observed for peak response and mean (i.e. over the 3 h following dosing) response. The mean FEV1 increase over baseline during the $3 \mathrm{~h}$ following dosing for tiotropium ranged $190 \pm 10-220 \pm 10 \mathrm{~mL}(19 \pm 1-22 \pm 1 \%)$; this was superior to placebo by $140 \pm 10-220 \pm 20 \mathrm{~mL}$. Figure 1 reveals

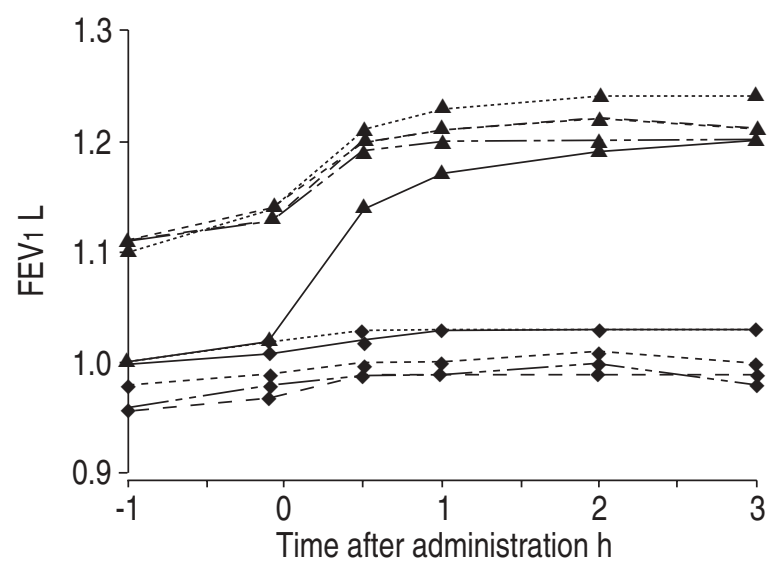

Fig. 1. - Mean response to tiotropium $(\boldsymbol{\Delta})$ or placebo $(\boldsymbol{\bullet})$ on days $1(-), 8(\cdots \cdots), 92(----), 176(---)$ and $344(-----)$ of the 1-yr trial. Note that the elevation over baseline prior to drug administration on days subsequent to the first treatment day in the tiotropium group is evidence of tiotropium's 24-h duration of action. The SEM for the mean differences between groups ranged $0.01-0.02 \mathrm{~L}$. FEV1: forced expiratory volume in one second. 
consistent bronchodilation (i.e. no tachyphylaxis) throughout the study. The FVC responses paralleled those of FEV1. Mean increase in trough FVC ranged $260 \pm 20-290 \pm 20 \mathrm{~mL}(12 \pm 1-13 \pm 1 \%)$ over baseline and ranged $420 \pm 20-510 \pm 20 \mathrm{~mL}(19 \pm 1-23 \pm 1 \%)$ over baseline during the $3 \mathrm{~h}$ following treatment.

\section{Peak expiratory flow rate}

PEFR was higher in the tiotropium group relative to placebo for both morning and evening measurements $(\mathrm{p}<0.05)$. Differences in weekly means for morning PEFR ranged $11 \pm 4-25 \pm 6 \mathrm{~L} \cdot \mathrm{min}^{-1}$ over the 1-yr period (fig. 2).

\section{Symptoms}

BDI scores indicated moderate impairment in each of the three domains at baseline. Significant improvements in breathlessness compared to baseline, as assessed using the TDI focal score, were achieved by the first assessment (day 50) and maintained for the entire year in the tiotropium group compared to placebo. Differences ranged $0.8 \pm 0.2-1.1 \pm 0.2(\mathrm{p}<0.001$
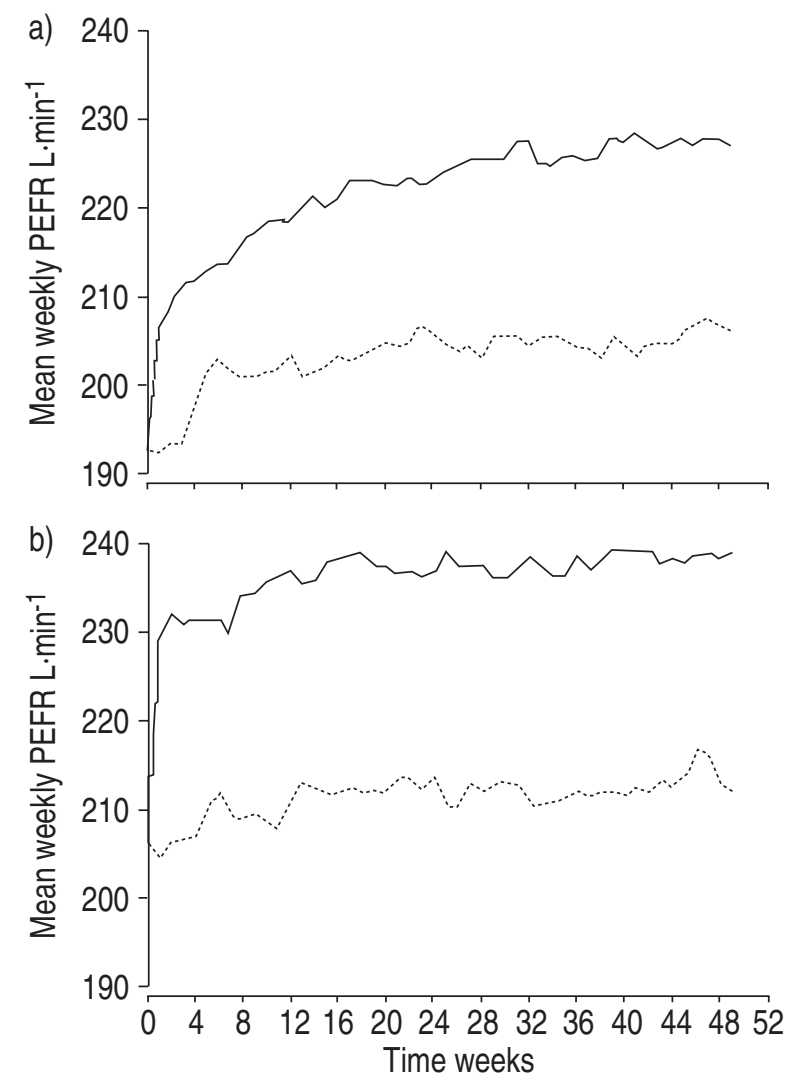

Fig. 2.-Mean peak expiratory flow rate (PEFR) measurements over the course of the 1-yr study for: a) morning; and b) evening assessments $(-$ : tiotropium $(n=507) ; \cdots \cdots \cdots$ : placebo $(n=332))$. The data represent weekly means. Differences between treatments were significant at all weeks $(\mathrm{p}<0.05)$. Means were adjusted for treatment, centre and baseline. The SEM for the mean difference between treatment groups ranged 3-6 $\mathrm{L} \cdot \mathrm{min}^{-1}$.

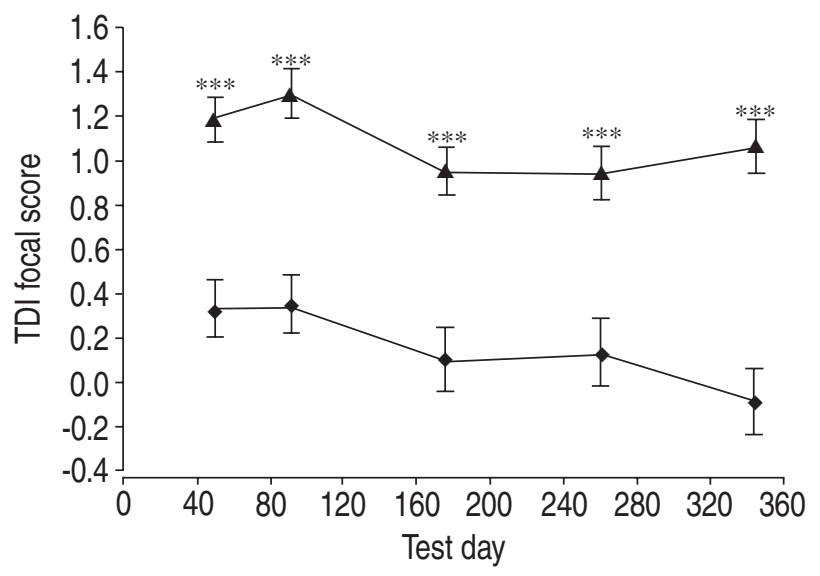

Fig. 3.-Mean Transition Dyspnea Index (TDI) focal score at the five assessment points over the course of the $1-y r$ trial ( $\boldsymbol{\Delta}$ : tiotropium $(\mathrm{n}=507) ; \diamond$ : placebo $(\mathrm{n}=325))$. Data are presented as mean \pm SEM. Means were adjusted for treatment, centre and Baseline Dyspnea Index. A higher score denotes less dyspnoea. $: \mathrm{p}<0.001$.

at all time points) (fig. 3). The proportion of patients who achieved a score of $\geqslant 1.0$ (corresponding to a clinically important difference) in TDI focal score was significantly greater in the tiotropium group at all five assessment points (42-47\%) than in the placebo group $(29-34 \%)(\mathrm{p}<0.01)$.

COPD symptom scores showed statistically significant improvements for shortness of breath and wheezing $(p<0.05)$, but not for cough and chest tightness, compared with placebo.

\section{Health outcomes}

Exacerbations. The proportion of patients experiencing at least one COPD exacerbation was lower in the tiotropium group $(36 \%)$ than in the placebo group $(42 \%)(14 \%$ reduction, $\mathrm{p}<0.05)$. There was a significant increase in the time to first exacerbation in the tiotropium group relative to placebo $(\mathrm{p}=0.011)$. There were significantly fewer exacerbations in the tiotropium group $\left(0.76\right.$ events $\cdot$ patient-yr $\left.{ }^{-1}\right)$ compared to those in the placebo group $\left(0.95\right.$ events $\cdot$ patient-yr $\left.{ }^{-1}\right)$, a $20 \%$ reduction $(\mathrm{p}=0.045)$. In addition, there were significantly fewer hospitalizations associated with exacerbations in the tiotropium group $\left(0.086\right.$ events patient-yr $\left.{ }^{-1}\right)$ compared to the placebo group $\left(0.161\right.$ events $\cdot$ patient-yr $\left.{ }^{-1}\right)$, a $47 \%$ reduction $(p=0.019)$. The proportion of patients hospitalized for exacerbation was lower in the tiotropium group $(5.5 \%)$ than in the placebo group $(9.4 \%, 41 \%$ reduction, $\mathrm{p}<0.05)$. Patients on tiotropium spent significantly fewer days in hospital for exacerbations ( 0.6 days $\cdot$ patient-yr $\left.^{-1}\right)$ compared with placebo (1.2 days'patient-yr ${ }^{-1}, 50 \%$ reduction, $\left.\mathrm{p}=0.023\right)$.

Chronic obstructive pulmonary disease-specific health status. Treatment-related changes in evaluation scores for health status, as assessed by the diseasespecific SGRQ, are shown in figure 4. Tiotropium demonstrated improvements in each domain as well 

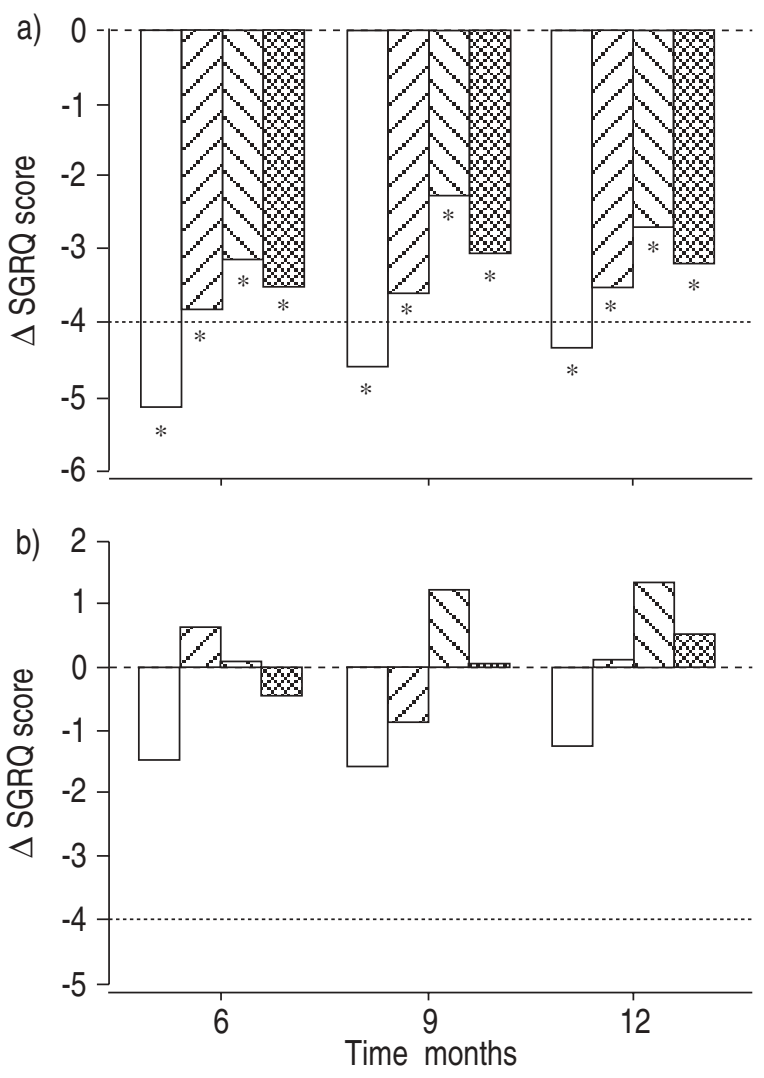

Fig. 4. - The mean total ( $\mathbf{0}$ ) and subscale (symptoms ( $\square$ ), activity $(\square)$ and impact $(\nabla))$ scores, in comparison to baseline, for the St George's Respiratory Questionnaire (SGRQ) at three assessment points in the 1-yr study for: a) tiotropium; and b) placebo. A lower score indicates an improvement in health status (....... clinically meaningful response (4-unit improvement)). $\Delta$ : change in. ${ }^{*}: \mathrm{p}<0.05$ versus placebo.

as in total score, with significant improvements observed relative to placebo $(p<0.05)$. In addition to a statistically significant improvement in mean response, a significantly greater percentage of patients in the tiotropium group (49\%) showed at least a fourunit improvement in total score, recognized as a clinically meaningful response, compared to those in the placebo group $(30 \%)$.

Generic health status. As documented by the SF-36, patients taking tiotropium demonstrated improvement in physical health domains relative to placebo (physical function, role physical and general health, as well as summary score) on all assessment days $(p<0.05)$. The mean improvements with tiotropium were 4.6 for physical function, 9.0 for role physical, 4.0 for general physical health and 2.4 for the physical summary score compared to placebo at the end of trial participation. There was no significant difference between treatment groups in the mental health summary, although significantly greater $(p<0.05)$ scores were observed for tiotropium in the domains of vitality and social function on four of five test days. The mean improvement with tiotropium was 3.2 for vitality and 3.9 for social function compared to placebo at the end of trial participation.
Table 2. - Adverse event profile

\begin{tabular}{lcc}
\hline & Tiotropium & Placebo \\
\hline Subjects n & 550 & 371 \\
Adverse events n (\%) & $495(90.0)$ & $338(91.1)$ \\
$\begin{array}{l}\text { Adverse events considered } \\
\quad \text { drug related n (\%) }\end{array}$ & $104(18.9)$ & $34(9.2)^{*}$ \\
Dry mouth n (\%) & $88(16.0)$ & $10(2.7)^{*}$ \\
$\begin{array}{l}\text { Deaths n (\%) } \\
\text { Serious adverse events n (\%) }\end{array}$ & $79(1.3)$ & $7(1.9)$ \\
$\quad$ Adverse events leading & $99(\%)$ & $78(21.0)$ \\
$\quad$ to discontinuation n (\%) & $53(9.6)$ & $51(13.7)$ \\
\hline
\end{tabular}

$*: \mathrm{p}<0.05$.

Medication use. Patients recorded their "as needed" doses of albuterol ( 1 dose is equivalent to $1-2$ puffs). The number of albuterol doses taken during the baseline period was comparable for the two treatment groups (tiotropium $3.7 \pm 0.12$ versus placebo $3.4 \pm 0.14$ doses $\left.\cdot \mathrm{day}^{-1}\right)$. During the last week of participation in the trial, mean albuterol use was $3.2 \pm 0.11$ and $4.1 \pm 0.13$ doses $\cdot$ day $^{-1}$ in the tiotropium and placebo groups, respectively $(\mathrm{p}<0.01)$.

Physician's global assessment. Patients in the tiotropium group showed greater improvement in physician's global evaluation than those in the placebo group on all test days $(\mathrm{p}<0.01)$. Physician's global evaluation scores ranged $4.94-5.05$ for the tiotropium group compared to $4.59-4.74$ for the placebo group over 11 visits throughout the year.

\section{Adverse effects}

The proportion of patients experiencing an adverse event over the course of the 1-yr study was similar in the tiotropium and placebo groups (table 2). The only adverse event which differed significantly between the groups was dry mouth, which occurred in $16 \%$ of tiotropium patients and $2.7 \%$ of placebo patients. Dry mouth was mild in the majority, and $<1 \%$ withdrew for this event. There were no significant differences in the proportion of patients with serious adverse events, in those withdrawing for adverse events or in deaths during the study (table 2).

\section{Discussion}

Bronchodilators are currently the mainstay of drug therapy for COPD [3]. The concept that airflow limitation in COPD is mainly irreversible is incorrect, as numerous studies have shown appreciable improvement in lung function with bronchodilator therapy in COPD patients not specifically selected based on standard reversibility criteria $[15,16]$. COPD appears to be more effectively treated by anticholinergic drugs than by sympathomimetics [3], probably due, in part, to the role of the cholinergic nervous system in controlling airway tone in these patients [4]. In current treatment guidelines, anticholinergics are recommended for maintenance therapy in COPD [1, 2, 8, 17]. 
The recent clinical development of tiotropium represents an advance in bronchodilator therapy in that its pharmacological features translate into clinically important attributes. Tiotropium binds significantly longer (hours) to the $\mathrm{M}_{3}$ muscarinic receptor (responsible for bronchodilation) than does ipratropium (minutes). This observation finds its clinical correlate in sustained improvements in airflow. Tiotropium also dissociates more rapidly from the $\mathrm{M}_{2}$ receptor (whose stimulation reduces acetylcholine release) than from the $\mathrm{M}_{3}$ receptor, antagonism of which promotes bronchodilation. Although functional correlates of these features have been demonstrated in experimental test systems of acetylcholine release and smooth muscle relaxation [18], the clinical effects of "kinetic receptor subtype selectivity" [19] have not been directly studied.

Single- [20] and multiple-dose [5] studies of tiotropium in COPD have demonstrated its prolonged duration of action. In a multiple-dose study of tiotropium, doses ranging 4.5-36 $\mu \mathrm{g}$ showed little dose dependency in spirometric outcomes, and the optimal therapeutic dose was judged to be $18 \mu \mathrm{g}$ [5]. The 24-h effectiveness of this dose was confirmed in a trial in which serial spirometry over the entire dosing interval demonstrated significant bronchodilation [21]. The first 13 weeks' spirometric results from one of the trials reported here have recently been published [22], and those findings were confirmed during the 1-yr study period. The elevation of trough FEV1 over baseline (fig. 1) demonstrates the appropriateness of once-daily administration. The persistence of FEV1 response over a full year of therapy indicates that tachyphylaxis does not occur during this time period. Higher evening PEFR responses in the tiotropium group (fig. 2b) are notable in light of their lesser use of rescue albuterol. The daily patient recordings of morning PEFR prior to dosing (fig. 2a) reinforce the concept that tiotropium's action persists for $\geqslant 24 \mathrm{~h}$.

Although spirometric assessment is important for the characterization of airflow impairment and improvements following therapy, other consequences of chronic disease relate to a patient's disability and handicap. Patients assigned to tiotropium experienced a significant improvement in dyspnoea relative to the placebo group, as assessed by the TDI. In addition, a significantly greater proportion of patients manifested an increase of $\geqslant 1$ unit on the TDI, a change that inherently reflects a clinically meaningful improvement based on the instrument's scoring description [12]; this is supported by analyses against general outcome measures [23]. The reduction in breathlessness with tiotropium is further supported by the significant reduction in the use of rescue albuterol as well as significant improvements in physician's global evaluation and the symptom diary rating of dyspnoea.

Alteration in COPD exacerbation frequency may be one of the most important health outcomes, as it significantly impacts upon the patient's quality of life [24] and is a major contributor to healthcare utilization [25]. In the present studies, tiotropium was associated with both fewer exacerbations and hospitalizations as well as prolonging the time to the first exacerbation. Treatment with inhaled corticosteroids has also been shown in some studies to reduce exacerbation rate $[26,27]$ and severity [28], suggesting a role for airway inflammation in disease exacerbation. In another report, salmeterol was associated with a prolonged time to exacerbation, but this study was limited to 3 months [29]. In another 12-week study, exacerbations were significantly reduced in patients treated with ipratropium plus salmeterol, but not salmeterol alone [30]. The mechanism(s) by which tiotropium reduces COPD exacerbations is not yet clear. Health status was improved with tiotropium relative to placebo, confirming the overall benefit of therapy to the patient. Improvements that were at or around the level of clinical significance (a decrease of 4 units) [14] were observed in all SGRQ domains compared with placebo. Further, a significantly higher proportion of patients exceeded a 4-unit improvement in the group receiving tiotropium. The largest difference between groups was observed in the impact domain of the SGRQ. This component reflects disturbances to everyday life imposed by the disease, including aspects of psychological distress as well as limitations put upon daily activities and social function. Although an unproved hypothesis, the reductions in dyspnoea and exacerbation frequency may account for the improvements seen in health status.

It is interesting to contrast these SGRQ score changes with those recently reported in COPD patients taking the inhaled glucocorticosteroid fluticasone (Inhaled Steroids in Obstructive Lung Disease (ISOLDE) trial, [26, 27]). That study assessed health status every 6 months over a 3 -yr period. Health status was shown to decline (rising SGRQ scores) in the group receiving placebo. Fluticasone reduced the rate of deterioration compared with placebo-treated patients, but at no time (including the first year) did fluticasone induce a significant improvement in health status. In contrast, although the overall observation period was shorter, the present study demonstrated that tiotropium produced an improvement in health status that was sustained over a $1-y r$ period. Few data are available with other interventions, particularly beyond 3 months of observation. Over 16 weeks, the $\beta$-agonist salmeterol has been reported to improve health status as measured by the SGRQ at $50 \mu \mathrm{g}$; it did not do so, however, at $100 \mu \mathrm{g}$ (both twice daily) [31]. Longer-term data are not available.

The present trial results indicate that tiotropium is an effective once-daily bronchodilator. Tiotropium was associated with consistent physiological and health outcome benefits including reduced dyspnoea, fewer exacerbations and improved health status; these benefits were sustained over a 1-yr period. Comparator 1-yr clinical trials versus ipratropium have been performed and indicate consistency of the improvements with tiotropium across multiple clinical outcomes [32]. Its attributes, defined in these long-term clinical trials, together with its demonstrated safety suggest that tiotropium is likely to provide an important contribution to the therapy of patients with symptomatic chronic obstructive pulmonary disease. 
Acknowledgements. The authors are grateful to the patients and their families, and the coordinators, nurses and therapists for their dedication to the study.

Participants: D. Amin, A. Anzueto, D. Auerbach, R. Baughman, H. Blumberg, S.A. Brazinski, R.D. Briggs, J.M. Cary, R. Casaburi, J.R. Castle, H. Chandarana, T. Craig, A.C. DeGraff, E. Diamond, J. Donohue, D.J. Elias, J. Flanders*, M. Friedman, M.D. Goldman, N.J. Gross, K. Gunther*, W.W. Henderson IV, F.C. Hiller, M. Janes, T.P. Kaine, J. Karpel, S. Kesten*, S. Knoper, P. Koch*, A. Kotch, T.S. Lemire, D. Levin, B. Levine, J. Liu, D. Mahler, M. Mandel, K.S. Miller, P. Montner, C.A. Piquette, R. Player, N. Pushlar*, J.W. Ramsdell, K. Reilly*, L. Repsher, D.A. Ruff, G. San Pedro, J.P. Schilling, J. Skatrud, D.D. Smith, J.A. Tita, J.D. Truwit, A. Wanner, J.G. Weg, I.M. Weisman, L.A. Weiss, R.L. ZuWallack (*Boehringer Ingelheim).

\section{References}

1. Ferguson GT, Cherniack RM. Management of chronic obstructive pulmonary disease. $N$ Engl J Med 1993; 32: 1017-1022.

2. Siafakas NM, Vermeire P, Pride NB, et al. Optimal assessment and management of chronic obstructive pulmonary disease (COPD). The European Respiratory Society Task Force. Eur Respir J 1995; 8: 13981420 .

3. Belman MJ, Botnick WC, Shin JW. Inhaled bronchodilators reduce dynamic hyperinflation during exercise in patients with chronic obstructive pulmonary disease. Am J Respir Crit Care Med 1996; 153: 967-975.

4. Gross NJ. Ipratropium bromide. N Engl J Med 1998; 319: 486-494

5. Littner MR, Ilowite JS, Tashkin DP, et al. Longacting bronchodilation with once-daily dosing of tiotropium (Spiriva) in stable chronic obstructive pulmonary disease. Am J Respir Crit Care Med 2000; 161: 1136-1142.

6. Disse B, Speck GA, Rominger KL, Witek TJ, Hammer R. Tiotropium (Spiriva): mechanistical considerations and clinical profile in obstructive lung disease. Life Sci 1999; 64: 457-464.

7. Witek TJ, Souhrada JF, Serby CW, Disse B. Tiotropium (Ba679). Pharmacology and early clinical observations. In: Spector SS, ed. Anticholinergics in the Upper and Lower Airways. New York, Marcel Dekker, Inc., 1999; pp. 137-152.

8. American Thoracic Society. Standards for the diagnosis and care of patients with chronic obstructive pulmonary disease (COPD). Am J Respir Crit Care Med 1995; 152: S77-S120.

9. Chodosh S, Flanders J, Serby CW, Kesten S, Hochrainer D, Witek TJ Jr. Effective use of Handihaler dry powder inhalation system over a range of COPD severity. J Aerosol Med 2001; 14: 309-315.

10. Morris JF, Koski A, Temple WP, Claremont A, Thomas DR. Fifteen year interval spirometric evaluation of the Oregon predictive equations. Chest 1988; 93: 123-127.

11. American Thoracic Society. Standardization of spirometry: 1994 update. Am J Respir Crit Care Med 1995; 152: 1107-1136.
12. Mahler DA, Weinberg DH, Wells CK, Feinstein AR. The measurement of dyspnea: contents, interobserver agreement and physiologic correlates of two new clinical indexes. Chest 1984; 85: 751-758.

13. Ware JE, Sherbourne CD. The MOS 36-item shortform health survey (SF-36): I. Conceptual framework and item selection. Med Care 1992; 30: 472-483.

14. Jones PW, Quirk FH, Baveystock CM, Littlejohns P. A self-complete measure for chronic airflow limitation - the St George's Respiratory Questionnaire. Am Rev Respir Dis 1992; 145: 1321-1327.

15. Dorinsky PM, Reisner C, Ferguson GT, Menjoge SS, Serby CW, Witek TJ Jr. The combination of ipratropium and albuterol optimizes pulmonary function reversibility testing in patients with COPD. Chest 1999; 115: 966-971.

16. Anthonisen NR, Wright EC, the IPPB Trial Group. Bronchodilator response in chronic obstructive pulmonary disease. Am Rev Respir Dis 1986; 133: 814-819.

17. Pauwels RA, Buist AS, Calverley PM, Jenkins CR, Hurd SS, and the GOLD Scientific Committee. Global strategy for the diagnosis, management, and prevention of chronic obstructive pulmonary disease. NHLBI/WHO Global Initiative for Chronic Obstructive Lung Disease (GOLD) Workshop summary. Am J Respir Crit Care Med 2001; 163: 1256-1276.

18. Takahashi T, Belvisi MG, Patel H, et al. Effect of Ba $679 \mathrm{BR}$, a novel long-acting anticholinergic agent, on cholinergic neurotransmission in guinea pig and human airways. Am J Respir Crit Care Med 1994; 150: $1640-1645$

19. Disse B, Witek TJ Jr. Anticholinergics: tiotropium. In: Hansel TT, Barnes PJ, eds. Progress in Respiratory Research. Vol. 31. New Drugs for Asthma, Allergy and COPD. London, Karger, 2000.

20. Maesen FPV, Smeets JJ, Sledsens TJH, Wald FDM, Cornelissen PJG. Tiotropium bromide, a new longacting antimuscarinic bronchodilator: a pharmacodynamic study in patients with chronic obstructive pulmonary disease (COPD). Eur Respir J 1995; 8: 1506-1513.

21. Calverly PMA, Towse LJ, Lee A. The timing of dose and pattern of bronchodilation of tiotropium (TIO) in stable COPD. Eur Respir J 2000; 16: Suppl. 31, 56S.

22. Casaburi R, Briggs D Jr, Donohue J, Serby CW, Menjoge SS, Witek TJ Jr. The spirometric efficacy of once-daily dosing with tiotropium in stable COPD: a 13-week multicenter trial. Chest 2000; 118: 1294 1302.

23. Witek TJ Jr, Mahler DA. The transition dyspnea index (TDI) in assessing improvements in breathlessness following tiotropium (TIO). Am J Respir Crit Care Med 2001; 163: A60.

24. Seemungal TA, Donaldson GC, Paul EA, Bestall JC, Jeffries DJ, Wedzicha JA. Effect of exacerbation on quality of life in patients with chronic obstructive pulmonary disease. Am J Respir Crit Care Med 1998; 157: 1418-1422.

25. Sullivan SD, Ramsey SD, Lee TA. The economic burden of COPD. Chest 2000; 117: Suppl., 5S-9S.

26. Burge PS, Calverly PM, Jones PW, Spencer S, Anderson JA, Maslen TK. Randomised, double blind, placebo controlled study of fluticasone propionate in patients with moderate to severe chronic obstructive pulmonary disease: the ISOLDE trial. BMJ 2000; 320: 1297-1303. 
27. Spencer S, Calverley PMA, Burge PS, Jones PW, on behalf of the ISOLDE Study Group. Health status deterioration in patients with chronic obstructive pulmonary disease. Am $\mathrm{J}$ Respir Crit Care Med 2001; 163: 122-128.

28. Paggiaro PL, Dahle R, Bakran I, Frith L, Hollingworth K, Efthimiou J. Multicentre randomised placebo-controlled trial of inhaled fluticasone propionate in patients with chronic obstructive pulmonary disease. Lancet 1998; 351: 773-780.

29. Mahler DA, Donohue JF, Barbee RA, et al. Efficacy of salmeterol xinafoate in the treatment of COPD. Chest 1999; 115: 957-965.
30. Van Noord JA, de Munck DRAJ, Bantje THA, Hop WCJ, Akveld MLM, Bommer AM. Long term treatment of chronic obstructive pulmonary disease with salmeterol and the additive effect of ipratropium. Eur Respir J 2000; 15: 878-885.

31. Jones PW, Bosh TK. Quality of life changes in COPD patients treated with salmeterol. Am J Respir Crit Care Med 1997; 155: 1283-1289.

32. Vincken W, van Noord JA, Greefhorst APM, et al., on behalf of the Dutch/Belgian Tiotropium Study Group. Improved health outcomes in patients with COPD during $1 \mathrm{yr}$ 's treatment with tiotropium. Eur Respir J 2002; 19: 209-216. 